\title{
Electrodes Modification Based on Metal-Free Phthalocyanine: Example of Electrochemical Sensors for the Detection of Acetic Acid
}

\author{
Amadou L. Ndiaye, ${ }^{1,2}$ Alain Pauly, ${ }^{1,2}$ Sebastien Delile, ${ }^{1,2}$ Jérôme Brunet, ${ }^{1,2}$ \\ Christelle Varenne, ${ }^{1,2}$ and Abhishek Kumar ${ }^{1,2}$ \\ ${ }^{1}$ Clermont Université, Université Blaise Pascal, Institut Pascal, BP 10448, 63000 Clermont-Ferrand, France \\ ${ }^{2}$ CNRS, UMR 6602, Institut Pascal, 63171 Aubiere, France
}

Correspondence should be addressed to Alain Pauly; alain.pauly@lasmea.univ-bpclermont.fr

Received 30 April 2015; Revised 10 July 2015; Accepted 14 July 2015

Academic Editor: Maria Luz Rodríguez-Méndez

\begin{abstract}
Copyright (C) 2015 Amadou L. Ndiaye et al. This is an open access article distributed under the Creative Commons Attribution License, which permits unrestricted use, distribution, and reproduction in any medium, provided the original work is properly cited.

Electroanalytical properties of tetra-tert-butyl phthalocyanine $\left(\mathrm{PcH}_{2}-\mathrm{tBu}\right)$ modified electrodes are studied by cyclic voltammetry $(\mathrm{CV})$. The modified electrodes are obtained by $\mathrm{CV}$ deposition techniques on gold (Au) and glassy carbon $(\mathrm{C})$ screenprinted electrodes (SPEs) and used for the electrochemical detection of acetic acid (AA). Based on the CV experiments, the electrodeposition mechanism is detailed. The modified $\mathrm{PcH}_{2}-\mathrm{tBu}$ electrodes reveal one oxidation and one reduction peak within the potential window of the working electrodes. In the presence of the analyte (acetic acid), the modified electrodes show sensitivity in the range of $10 \mathrm{mM}$ to $400 \mathrm{mM}$. For the $\mathrm{PcH}_{2}$-tBu modified Au electrode, a limit of detection (LOD) of $5.89 \mathrm{mM}$ (based on the $+0.06 \mathrm{~V}$ peak) was obtained while for the $\mathrm{PcH}_{2}-\mathrm{tBu}$ modified $\mathrm{C}$ electrode a LOD of $17.76 \mathrm{mM}$ (based on the $+0.07 \mathrm{~V}$ peak) was achieved. A signal decay of $17 \%$, based on 20 experiments, is obtained when gold is used as working electrode. If carbon is used as working electrode a value of $7 \%$ is attained. A signal decay is observed after more than 50 cycles of experiments and is more pronounced when higher concentrations of acetic acid are used. A mechanism of sensing is proposed at the end.
\end{abstract}

\section{Introduction}

Acetic acid (AA) represents one of the most abundantly produced volatile fatty acids (VFAs) $[1,2]$. Its monitoring is necessary for the optimization of biogas or biofuel production [1-4]. The current methods to control such process are conventionally based on distillation and colorimetric and chromatographic techniques [5]. Most of these methods required specific equipment and are time and space consuming. Other methods use catalytic reforming which necessitated specific working condition (high temperature, use of a catalyst, etc.) but they are considered as "destructive methods" since the VFAs are completely transformed at the end [6-10].

If the previous cited methods are well documented, other methods based on use of electrochemical approaches are less explored. This observation can be explained by two aspects: (i) a direct oxidation or reduction of acetic acid is very difficult to achieve in conventional electrochemistry and (ii) the use of biosensors based on the grafting of enzyme or biomolecules able to detect the VFAs requires specific conditioning.

In front of this finding, it seems essential to develop an indirect method, that is, to find an electrochemical signal, which would generate different response in the presence of acetic acid. Such a feature can be fully achieved using, for example, electrochemically modified electrodes. Macrocycles (MCs) like phthalocyanines derivatives are known for their suitability to perform electrode modification. Several phthalocyanines have been investigated for application devoted to electrocatalysis [11-13] and also for sensing purpose [14-18].

It has been demonstrated that the $\mathrm{PcH}_{2}$ molecules can react with acetic acid in solutions (mix of acids). In such reaction, the protonation of the phthalocyanine can occur 
mainly in the meso-nitrogen position [19]. Moreover, other studies $[20,21]$ described some phthalocyanines derivatives as multicenter conjugated systems with simultaneous acid and base properties. Even if in the article of Gaberkorn et al. [19] higher concentration of acetic acid is used, the presence of the acetic acid seems to initiate the protonation, which can affect the HOMO-LUMO band gap. This idea will be explored in our study. Since the $\mathrm{PcH}_{2}$ is not soluble in organic solvent, its tetra-butyl derivative $\left(\mathrm{PcH}_{2} \mathrm{tBu}\right)$, which is more soluble, will be used as sensing material for the electroanalytical investigation.

Here we have realized the electrode modification of a gold and glassy carbon working electrode using a metalfree phthalocyanine $\left(\mathrm{PcH}_{2} \mathrm{tBu}\right)$. First, the deposition process has been achieved by cyclic voltammetry and then the effectiveness of the electrode modification is revealed through characterization using CV techniques. Finally, the electroanalytical performance of the $\mathrm{PcH}_{2} \mathrm{tBu}$-based modified electrodes towards acetic acid detection is highlighted by CV experiments.

\section{Materials and Methods}

2.1. Reagents. All reagents were of analytical grade and were purchased from Aldrich. Anhydrous chloroform $\left(\mathrm{CHCl}_{3}\right.$, purity grade $>99 \%$ ) and acetonitrile (ACN) were used as solvent without further purification procedure. 2,9,16,23-Tetratert-butyl-29H,31H-phthalocyanine (purity 97\%), denoted by $\mathrm{PcH}_{2} \mathrm{tBu}$, was used as sensing material. For electrochemical investigation, tetrabutylammonium tetrafluoroborate (TBAB), $\mathrm{H}_{2} \mathrm{SO}_{4}(0.5 \mathrm{M})$, and $\mathrm{KCl}(3 \mathrm{M})$ were used as electrolyte while acetic acid (AA) was used as analyte.

2.2. Apparatus. All measurements were carried out at room temperature. Electrochemical measurements were performed with a $\mu$ STAT 200 potentiostat (DropSens, Oviedo, Spain) controlled by a DropView software. The electrodes consist of screen-printed electrodes (SPEs) (DRP C110 and DRP C220AT, DropSens, Oviedo, Spain) based on a configuration where working, counter, and reference electrode are localized on the same electrode support $[14,22]$. The working ( $4 \mathrm{~mm}$ in diameter) and counter electrodes are made of glassy carbon (C, DRP C110) or gold (Au, DRP C220AT) while the reference electrode is made of silver (Ag, in both SPEs). Such SPEs have been already used in related literature for electrode modification purpose [14, 22-24].

2.3. Electrodes Modifications by Cyclic Voltammetry. All solutions were freshly prepared before the experiments and deionized water was used for aqueous phase. For a general procedure, the solutions are prepared by dissolving the $\mathrm{PcH}_{2} \mathrm{tBu}$ in a solvent $(0.1 \mathrm{mM}$ to $1 \mathrm{mM})$ followed by adding $\mathrm{TBAB}$ as electrolyte. Before the electrodeposition experiment, the solution was thoroughly stirred and finally immersed into an ultrasonic bath for 5 to 10 minutes.

Prior to any deposition, the electrodes were cleaned in a $0.5 \mathrm{M} \mathrm{H}_{2} \mathrm{SO}_{4}$. The cleaning process consists of a repetitive cycling of the electrode in a $0.5 \mathrm{M} \mathrm{H}_{2} \mathrm{SO}_{4}$ solution between
$-0.1 \mathrm{~V}$ and $+1 \mathrm{~V}$ (for the Au working electrode) or from -1 to $+1 \mathrm{~V}$ (for the $\mathrm{C}$ working electrode) with a scan rate of $0.1 \mathrm{~V} / \mathrm{s}$. The end of the cleaning process is determined by the number of cycles at which the last ten subsequent cycles were identical.

In a typical process of electrodeposition, the electrodes were immersed into a solution containing $\mathrm{PcH}_{2} \mathrm{tBu}(0.2 \mathrm{mM})$ material in a $\mathrm{CHCl}_{3} / \mathrm{ACN}$ (1:4 volume ratio) solution with TBAB $(0.1 \mathrm{M})$. The deposition process is carried out by scanning within a predefined potential window at a scan rate of $0.1 \mathrm{~V} / \mathrm{s}$. The modified electrodes will be denoted by $C S P E-$ $\mathrm{PCH}_{2} t \mathrm{Bu}$ and $\mathrm{Au} S P E-\mathrm{PcH}_{2} t \mathrm{Bu}$ in the following part of this paper.

2.4. Acetic Acid Detection Experiments. For the acetic acid detection experiments, $\mathrm{KCl}$ was used as electrolyte. Stock solutions of acetic acid ( $1 \mathrm{mM}$ to $500 \mathrm{mM})$ were prepared from concentrated acetic acid solutions dissolved in $0.1 \mathrm{M}$ of $\mathrm{KCl}$. The cyclic voltammetry experiments were performed on aqueous media, and the working potential was delimited to be $-0.5 \mathrm{~V}$ to $+1 \mathrm{~V}$ and $-0.3 \mathrm{~V}$ to $+0.8 \mathrm{~V}$ for carbon and gold electrodes, respectively.

\section{Result and Discussion}

3.1. Electrode Modification by Cyclic Voltammetry. Electrodes modification based on the use of phthalocyanines derivatives $[25,26]$ or other moieties [27] is already reported. Generally a repetitive cycling is performed on the electrode dipped into the solution containing the materials to achieve the electrodeposition. Due to solvent compatibility with SPEs in our case, the deposition was conducted using a wellestablished method resulting from our preliminary experiments (not shown here) in which we found that using a solvent mixture can prevent electrode alteration. For a general procedure, the $\mathrm{PcH}_{2} \mathrm{tBu}$ was dissolved in the solvent mixture which consists of $\mathrm{CHCl}_{3} / \mathrm{ACN}$ (1:4 volume ratio) and finally TBAB $(0.1 \mathrm{M})$ was added. The electrodeposition was performed by repetitive scanning from -1 to $1 \mathrm{~V}$ at a scan rate of $0.1 \mathrm{~V} / \mathrm{s}$. Figure 1 shows the $\mathrm{CV}$ curves recorded during the electrodeposition process of $\mathrm{PcH}_{2} \mathrm{tBu}$ materials. After 10 cycles the cyclic voltammogram presents peaks which can be assigned to phthalocyanines ring-based redox processes $[26,28]$ as being the dominant electrochemical process in phthalocyanine-based materials [29].

We first performed a series of experiments to optimize the electrodeposition. This optimization is obtained by recording the peak current located at $-0.15 \mathrm{~V}$, for example, as function of the scan number (see inset in Figure 1). In the first scan, the $\mathrm{PcH}_{2} \mathrm{tBu}$ redox peaks are not well identified, but in the following scans they become more and more intense. We can see that the current peak at $-0.16 \mathrm{~V}$ increases with the scan number. However, a very fast growth of the current peak is recorded within scans numbers 25 and 85. After more than 100 scans, an electrode alteration was visible. Moreover, we remark that the deposited layer, obtained after more than 100 scans, was easily removed (accidentally) from the electrode just upon rinsing the electrode. We therefore 


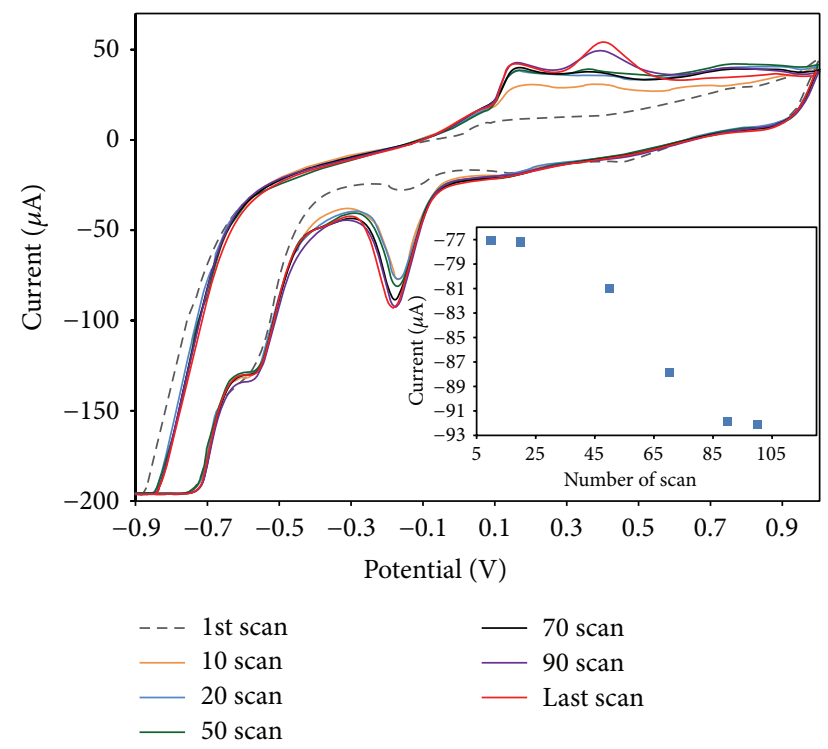

FIgure 1: Repetitive cyclic voltammogram of the $\mathrm{PcH}_{2} \mathrm{tBu}$ showing the film formation onto a gold electrode. Inset shows the current peak as function of the number of scans based on the peak around $-0.16 \mathrm{~V}$.

defined a number of 100 scans as an optimum for the electrode modification.

A general mechanism of formation of the layer is not well established for the electrodeposition process for phthalocyanine derivatives. Generally, the change of the voltammogram while increasing the number of scans is used to evidence an electrode modification [26, 28]. De Wael et al. [30] explained the electrodeposition as multistep formation process while Ilangovan et al. [31] suggest a mechanism following nucleation and growth. To explain the electrodeposition process, we have focused on $\mathrm{CV}$ curves in Figure 1. In the first scans, the small peaks attributed to the $\mathrm{PcH}_{2} \mathrm{tBu}$ start to increase. The reduction peaks at $-0.15 \mathrm{~V}$ and the oxidation one at $+0.14 \mathrm{~V}$ increase simultaneously, which means that these two peaks are associated. The small current variation in the beginning of the $\mathrm{CV}$ cycling illustrates adsorption process of the $\mathrm{PcH}_{2} \mathrm{tBu}$ molecules. This adsorption phase occurs randomly and is described as a chaotic orientation of the phthalocyanines molecules [32]. This happens during the first ten cycles. After this adsorption phase, the $\mathrm{PcH}_{2} \mathrm{tBu}$ molecules start to organize on the electrode surface in a more ordered way (stacking or columnar growth). This organization explained the increasing current density accompanied by the small shift in the potentials (from $-0.15 \mathrm{~V}$ to $-0.17 \mathrm{~V}$ ). Such a simultaneous peak shift and current increase during electrodeposition are generally indicative of a change on the surface attributed to deposition $[33,34]$. This second stage occurs until 80 scans. At the end, the formed layers are dense enough to prevent any further molecules to be deposited. This last stage is corresponding to a saturation and is illustrated by the stagnation of the current density. So we can suggest here also a multiphase process leading to electrodeposition: (i) random adsorption, (ii) ordered

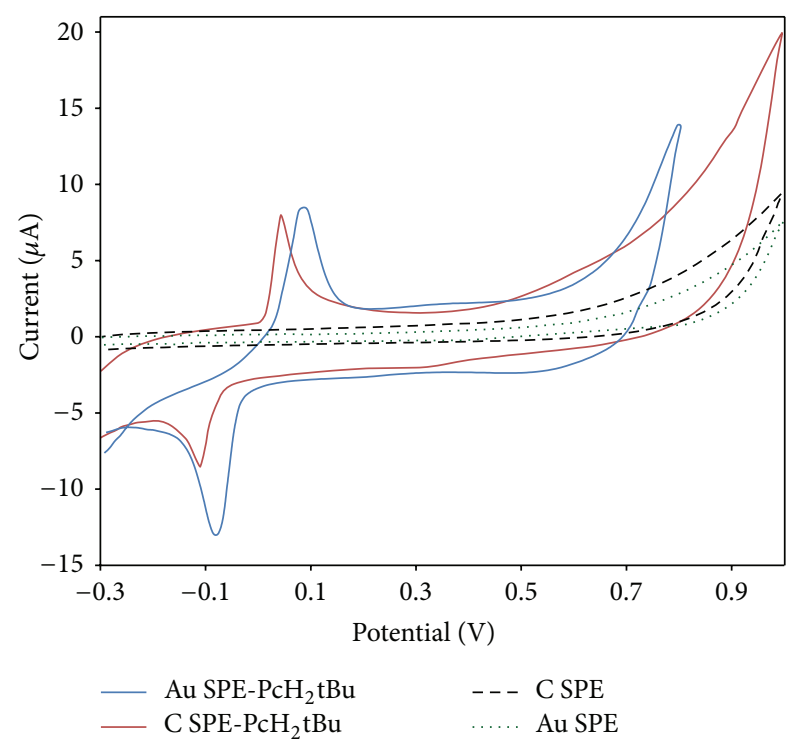

FIGURE 2: CV studies of the modified electrodes revealing the redox peaks of the $\mathrm{PcH}_{2} \mathrm{tBu}$ in $\mathrm{KCl} 0.1 \mathrm{M}$. For comparison the cyclic voltamogramm of the bare electrodes on the $\mathrm{KCl}$ solution are shown.

growth, and (iii) saturation due to formation of a barrier (thickness dependent). The potential peak around $0.41 \mathrm{~V}$ follows a nonhomogenous growth. Its formation seems to start after 70 scans. This peak is attributed to the formation of adsorbed aggregates. This is further confirmed during electrochemical characterization where a simple rinsing of the electrode leads to a disappearance of the peak at $0.41 \mathrm{~V}$.

For the $\mathrm{C}$ working electrode (not shown here) we were not able to identify the well-defined peaks. This is due to the very large background current which makes the faradic peaks imperceptible in our working conditions.

3.2. Characterization of the Modified Electrodes. We have first performed CV studies of the bare electrodes to delimit the electrochemical window for using these electrodes in aqueous media and also in the presence of the analyte. It comes out from this study that the working potential range for $\mathrm{C}$ electrode and gold electrodes is delimited to $-0.5 \mathrm{~V}$ to $+1 \mathrm{~V}$ and $-0.3 \mathrm{~V}$ to $+0.8 \mathrm{~V}$, respectively. To characterize the coating, we have performed cyclic voltammetry experiments of the modified electrodes in $\mathrm{KCl}(0.1 \mathrm{M})$ and for comparison the cyclic voltammograms of the bare electrodes are also presented in the same graph.

The results are shown in Figure 2. A potential sweep from $-0.3 \mathrm{~V}$ to $0.8 \mathrm{~V}$ in $0.1 \mathrm{M} \mathrm{KCl}$ reveals for the $\mathrm{Au}$ $\mathrm{SPE}-\mathrm{PCH}_{2} \mathrm{tBu}$ an oxidation wave with a peak at $+0.09 \mathrm{~V}$, which forms with the reduction peak located at $-0.07 \mathrm{~V}$ a quasireversible couple. An identical result is observed for the $\mathrm{C}$ SPE- $\mathrm{PcH}_{2} \mathrm{tBu}$ with two peaks localized at $+0.04 \mathrm{~V}$ and $-0.12 \mathrm{~V}$. No electrochemical signals are obtained when $\mathrm{CV}$ experiments are realized on bare electrodes in the same conditions. Therefore, we could undoubtedly attribute these peaks as arising from the $\mathrm{PcH}_{2} \mathrm{tBu}$. Compared to the $\mathrm{CV}$ obtained during the electrodeposition, the $\mathrm{Au} \mathrm{SPE}-\mathrm{PcH}_{2} \mathrm{tBu}$ 
peaks are shifted (from $+0.15 \mathrm{~V}$ to $+0.09 \mathrm{~V}$ and from $-0.17 \mathrm{~V}$ to $-0.07 \mathrm{~V})$. These shifts are mainly attributed to change in the experimental media and solvent nature. For both modified electrodes, $\Delta \mathrm{Ep}\left(\mathrm{Ep}_{a}-\mathrm{Ep}_{c}\right)$ is greater than $150 \mathrm{mV}$ while $\mathrm{Ip}_{a} / \mathrm{Ip}_{c}$ ratio is less than 1 , suggesting a quasireversible process. The deviation from reversibility in such compounds is mainly attributed to aggregation [26]. We have also noticed in some cases that around $+0.8 \mathrm{~V}$ the $\mathrm{Au}$ electrode starts to oxidize. For this reason, we have performed the same experiments under nitrogen. We observed that experiments conducted under aerated condition and nitrogen bubbling do not show any differences in the peak potential positioning or intensity within the potential window from $-0.3 \mathrm{~V}$ to $0.8 \mathrm{~V}$; for this reason we have performed the rest of the experiences without nitrogen. Of course the effect of oxygen is observed at a higher reduction potential $(\sim-0.6 \mathrm{~V}$ to $-0.7 \mathrm{~V})$.

The deposit seems to be more stable on the carbon electrode compared to the gold electrode. Taking into account the fact that the carbon electrode contains graphitic layers, this behavior can be explained by the possibility of the $\mathrm{PcH}_{2} \mathrm{tBu}$ to interact with the carbon electrode via $\pi-\pi$ interaction. This kind of interaction favored the preliminary adsorption of the molecules before the electrodeposition starts. Such a noncovalent interaction is established when carbon nanotubes, for example, are functionalized by phthalocyanines derivatives [35].

3.3. Acetic Acid Detection. Cyclic voltammetry was employed in order to test the electrochemical sensor. As shown in Figure 3, cyclic voltammograms of the $\mathrm{Au} \mathrm{SPE}-\mathrm{PcH}_{2} \mathrm{tBu}$ modified electrodes at different acetic acid concentrations were recorded. At acetic acid concentration of $0.01 \mathrm{M}$ an oxidation peak located around $+0.06 \mathrm{~V}$ dominates the voltammogram. As the concentration of acid increases, the current intensity increases and the peaks become less broadened. At higher concentration (around $0.2 \mathrm{M}$ ) the current stops increasing and this observation indicates that a saturation occurs. The same saturation peaks were obtained for 0.4 and $0.5 \mathrm{M}$ (not shown here). The sensors obtained with our electrodeposition method display a linear response to acetic acid in the range of $10 \mathrm{mM}-200 \mathrm{mM}$ (inset in Figure 3) with a correlation coefficient $R^{2}$ of $0.85 . R^{2}$ value can attain 0.98 if only the range of $10 \mathrm{mM}-100 \mathrm{mM}$ is evaluated. This improved $R^{2}$ value (0.98) shows that the saturation starts already with the $200 \mathrm{mM}$ concentration of acetic acid. At higher concentrations $(>200 \mathrm{mM})$ the calibration curve deviates from linearity due to the saturation of the sensor.

From the calibration curve (inset in Figure 3), we have evaluated the limit of detection (LOD). The limit of detection is calculated following $3 \mathrm{SD} / m$ criterion, as already published [36], where $m$ is the slope of the calibration graph and SD is the standard deviation of the voltammetric signal at the lowest concentration. We can calculate a LOD of $5.89 \mathrm{mM}$ from the anodic peak at ca. $+0.06 \mathrm{~V}$.

In the case of $\mathrm{CSPE}-\mathrm{PCH}_{2} t \mathrm{Bu}$, a similar trend is observed, except that the saturation phenomenon occurs at higher concentration $(>400 \mathrm{mM})$ and the lowest attainable concentration is $50 \mathrm{mM}$. Figure 4 represents the $\mathrm{CV}$ of the

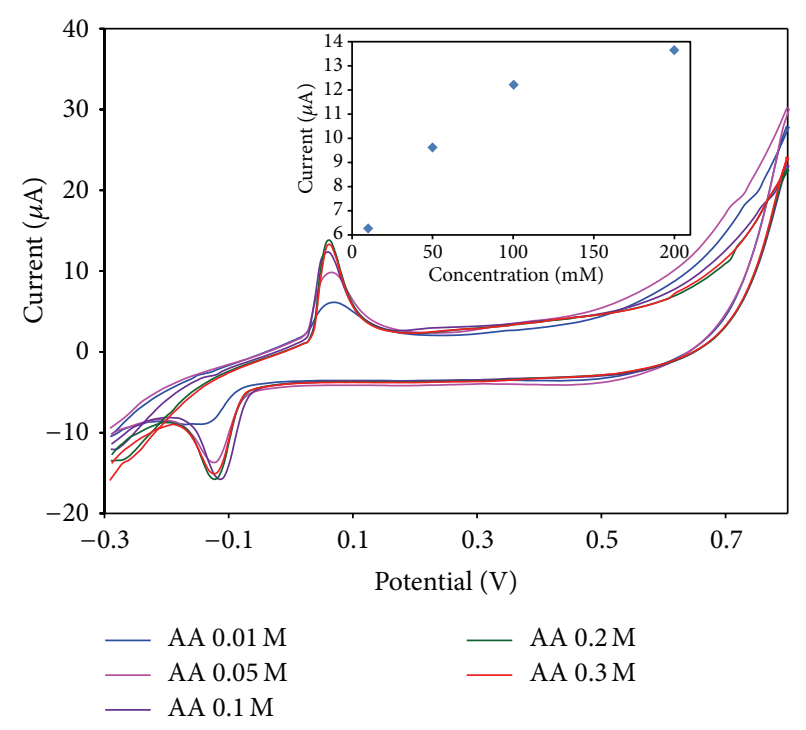

Figure 3: CV curves of $\mathrm{Au} \mathrm{SPE}-\mathrm{PcH}_{2} \mathrm{tBu}$ with addition of the acetic acid. Scan rate $=0.1 \mathrm{~V} / \mathrm{s}$. Inset represents the calibration curves obtained from the anodic peak current as function of the concentration. Note that the curve for the AA $0.3 \mathrm{M}$ is only represented here to point the saturation phenomenon.

C SPE- $\mathrm{PCH}_{2} \mathrm{tBu}$ modified electrode upon addition of acetic acid. A small increase is observed in the lower concentration range while a linear increase dominates in the range of $100 \mathrm{mM}$ to $400 \mathrm{mM}$. As previously observed, in this case also, the current intensity increases with the concentration of acetic acid. The sensor displays a linear response to acetic acid in the range of $50 \mathrm{mM}-400 \mathrm{mM}$ (inset in Figure 4) with a correlation coefficient $R^{2}$ of 0.94 . Here again, $R^{2}$ value can attain 0.99 if only the range of $50 \mathrm{mM}-300 \mathrm{mM}$ is evaluated. This improved $R^{2}$ value (0.99) shows again that the saturation starts around $400 \mathrm{mM}$ concentration of acetic acid. This was further confirmed in our analysis by recording the $\mathrm{CV}$ at $500 \mathrm{mM}$ (not shown here). We obtained a LOD of $21.76 \mathrm{mM}$ from the anodic peak at ca. $+0.07 \mathrm{~V}$.

In both cases $\left(C S P E-P c H_{2} t B u\right.$ and $\left.A u S P E-P c H_{2} t B u\right)$, current versus concentration analysis revealed a linear dependence between the current peak and the analyte concentration (see insets in Figures 3 and 4); however the two sensors present different concentration ranges and LOD. This can be explained by two factors: (i) the better electrocatalytical activity of gold electrode compared to glassy carbon electrode, which allows a better sensitivity at lower concentration, and (ii) a better anchoring of the $\mathrm{PcH}_{2} \mathrm{tBu}$ molecules on the carbon electrode probably initiated by the $\pi-\pi$ interaction. Another explanation can arise from the surface structuration of the sensing layer which can affect the numbers of active sites available for the analyte molecules. It is worth noting that there is not enough data available to compare our sensors data with published ones in terms of LOD and concentration range using the electrochemical methods for acetic acid detection. Therefore we could not provide comparison data.

Finally, we have conducted electrochemical experiment on the modified electrodes to characterize the nature of 


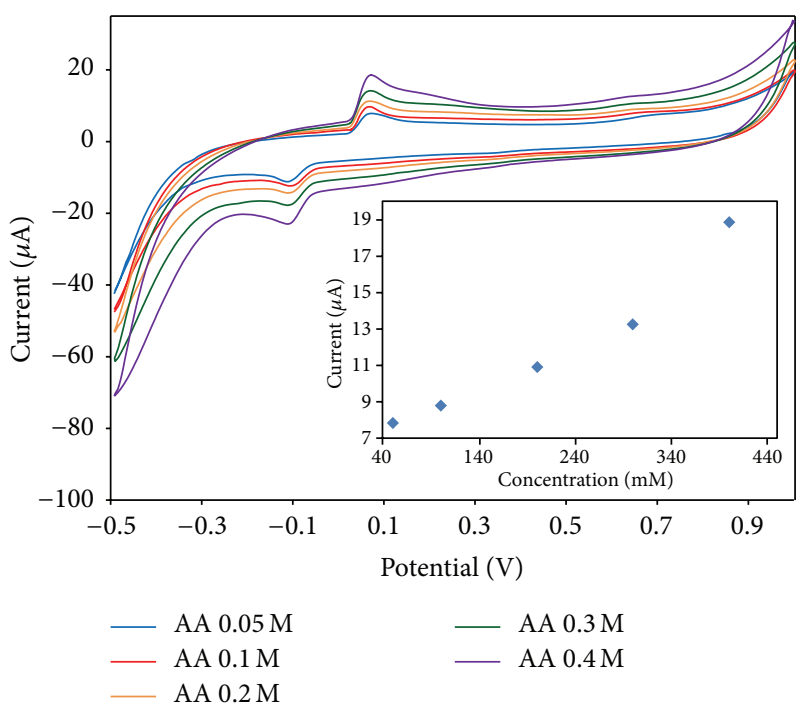

FIgure 4: $\mathrm{CV}$ curves of $\mathrm{C}$ SPE- $\mathrm{PcH}_{2} \mathrm{tBu}$ with addition of the acetic acid. Scan rate $=0.1 \mathrm{~V} / \mathrm{s}$. Inset represents the calibration curves obtained from the anodic peak current as function of the concentration.

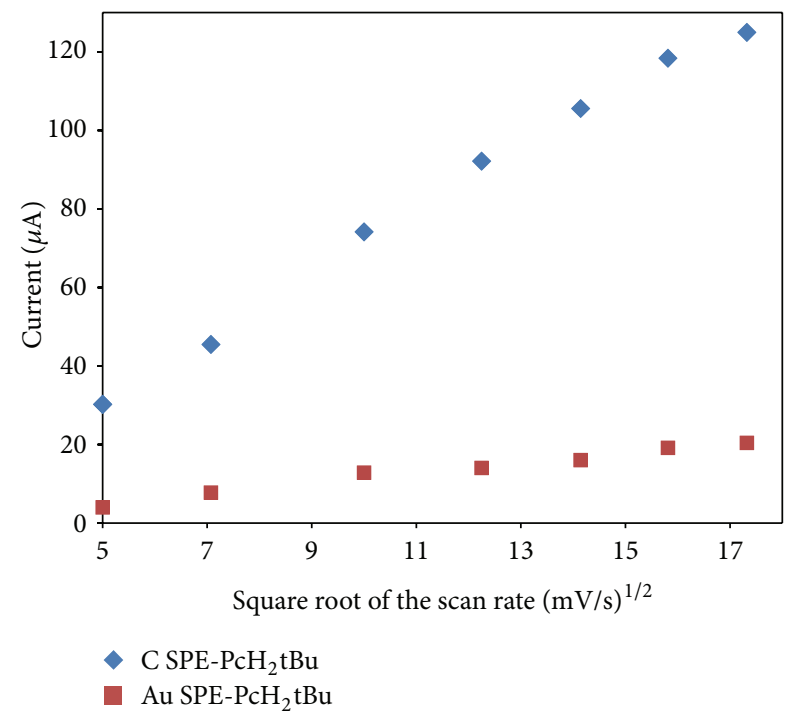

FIGURE 5: The current evolution of modified electrodes as function of the square root of the scan rate in a $0.1 \mathrm{M}$ acetic acid solution.

the redox process in the presence of the analyte. This study has been performed in a $0.1 \mathrm{M}$ acetic acid solution while increasing the scan rate from 25 to $300 \mathrm{mV} / \mathrm{s}$. Figure 5 shows the current recorded as function of square root of the scan rate in a $0.1 \mathrm{M}$ acetic acid concentration for the two modified electrodes. An increase of the scan rate gives rise to an increase of the current peak as shown in Figure 5.

The modified electrodes show a linear dependence of the anodic peak current with the square root of the scan rate. The linearity observed in Figure 5 is also attested by the regression coefficient $\left(R^{2}\right)$ value $\left(R^{2}=0.9938\right.$ for $C$ $S P E-P c H_{2} t B u$ and $R^{2}=0.9821$ for $\left.A u S P E-P c H_{2} t B u\right)$ and is indicative of a predominant diffusion-controlled redox process. The difference in slopes is attributed to the difference in the nature of the electrode material. It is important to mention that this linear evolution of the current as function of the scan rate is also accompanied by a shift of the potential peak (not shown here). In fact, for both modified electrodes, $\Delta \mathrm{Ep}\left(\mathrm{Ep}_{a}-\mathrm{Ep}_{c}\right)$ separation value increases with the scan rate. This evolution is characteristic of a quasireversible process and confirms the precedent results discussed in Section 3.2.

Besides the small intensity variation, the modified electrodes show potentiality to be used as electrochemical sensors for the acetic acid detection. Therefore, in this paragraph, we have focused on the possible sensing mechanism. The reaction of acetic acid on phthalocyanine induces mainly a protonation. And this assumption has been already proven by spectroscopic studies by Gaberkorn et al. [19] in the case of the $\mathrm{PcH}_{2}$. This protonation induces a change in the HOMO/LUMO band gap positioning causing a shift in UVvisible spectra. Concomitantly, this perturbation will induce a change on the positioning of the peak potential since the electrochemical signal involved electron's promotion from the HOMO or LUMO energy levels. Once protonated, the $\mathrm{PcH}_{2} \mathrm{tBu}$ can also interact with the acetate anion which possesses high coordinating power. We can imagine that the acetate anion will also coordinate the protonated molecules. Accordingly, we proposed a two-step mechanism: a first step leading to a protonation and the subsequent coordination of the deprotonated analyte (acetate) and/or normal form (acetic acid). Nevertheless, the simple coordination of acetic acid (not deprotonated) in its normal form is also possible. Moreover, hydrogen bonding interaction can be also initiated between the macrocycle ring and the acetic acid.

We have also evaluated the reproducibility and the lifetime of the electrochemical sensors. For this study, the $0.1 \mathrm{M}$ acetic acid has been used in 20 successive experiments. A general current signal decreasing is notified and this effect is more pronounced in the Au electrode. Indeed, the percentage current decay is $17 \%$, based on 20 experiments, when gold is used as working electrode, while this value averages $7 \%$ for the carbon electrodes. After several experiments also new peaks coming probably from the Au electrodes oxidation are identified for the $\mathrm{Au} S P E-\mathrm{PcH}_{2} t B u$. In summary, after 40 to 50 experiments, the sensors show a general alteration which is characterized by a pronounced flattening of the current peaks. The lifetime has been set to $50 \mathrm{CV}$ cycles. This effect is more accelerated when higher acetic acid concentration is used. Even if the LOD has to be improved and the coating has to be further optimized, these modified electrodes (if they are freshly prepared) can be used for acid acetic detection.

\section{Conclusion}

Here we investigate the possibility to modify SPEs with metal-free phthalocyanines derivatives. The easy to handle electrodes can be modified by attaching organic macrocycles and the characterization by cyclic voltammetry evidences the electrode modification. The gold modified electrode presents a LOD of $5.89 \mathrm{mM}$ in the concentration range of 
$10 \mathrm{mM}-200 \mathrm{mM}$. This low LOD is attributed to the better electrocatalytic properties of gold. However its percentage of current decay averaging the $17 \%$ as well as the rapid aging effects limits its use. For the carbon modified electrodes the limit of detection is slightly higher $(17.76 \mathrm{mM})$ but a better percentage of current decay $(7 \%)$ is obtained. Taking into account the fact that these kinds of SPEs are disposable, this observation is not a shortcoming at all, since freshly prepared electrodes can realize up to 50 experiences. We show here that these modified electrodes can detect acetic acid. The proposed detection mechanism follows a protonation and subsequent coordination of the analyte. Of course, attempts to improve the process and to lower the detection limit will be further investigated as a continuation. This work opens a new window on the utilization of macrocycles based material for acid acetic detection and settles new ideas for VFA detection.

\section{Conflict of Interests}

The authors declare that there is no conflict of interests regarding the publication of this paper.

\section{Acknowledgments}

This work has been sponsored by the French government research program "Investissements d'avenir" through the IMobS3 Laboratory of Excellence (ANR-10-LABX-16-01), by the European Union through the program regional competitiveness and employment 2007-2013 (ERDF, Auvergne region), and by the Auvergne region. Amadou L. Ndiaye and Sebastien Delile thank the "Laboratoire d'Excellence IMobS3" for postdoctoral fellowships. Jérôme Brunet, Alain Pauly, and Amadou L. Ndiaye would like to thank the transdisciplinary COST Action TD 1105 "EuNetAir" in which they are involved for supporting these scientific activities.

\section{References}

[1] A. Zhou, Z. Guo, C. Yang, F. Kong, W. Liu, and A. Wang, "Volatile fatty acids productivity by anaerobic co-digesting waste activated sludge and corn straw: effect of feedstock proportion," Journal of Biotechnology, vol. 168, no. 2, pp. 234239, 2013.

[2] H. N. Chang, N.-J. Kim, J. Kang, and C. M. Jeong, "Biomassderived volatile fatty acid platform for fuels and chemicals," Biotechnology and Bioprocess Engineering, vol. 15, no. 1, pp. 1-10, 2010.

[3] P. F. Pind, I. Angelidaki, and B. K. Ahring, "Dynamics of the anaerobic process: effects of volatile fatty acids," Biotechnology and Bioengineering, vol. 82, no. 7, pp. 791-801, 2003.

[4] L. Appels, A. V. Assche, K. Willems, J. Degrève, J. V. Impe, and R. Dewil, "Peracetic acid oxidation as an alternative pretreatment for the anaerobic digestion of waste activated sludge," Bioresource Technology, vol. 102, no. 5, pp. 4124-4130, 2011.

[5] O. Lahav, B. E. Morgan, and R. E. Loewenthal, "Rapid, simple, and accurate method for measurement of VFA and carbonate alkalinity in anaerobic reactors," Environmental Science \& Technology, vol. 36, no. 12, pp. 2736-2741, 2002.

[6] Y. Chen, L. Yuan, T. Ye et al., "Effects of current upon hydrogen production from electrochemical catalytic reforming of acetic acid," International Journal of Hydrogen Energy, vol. 34, no. 4, pp. 1760-1770, 2009.

[7] J. Barbier Jr., F. Delanöe, F. Jabouille, D. Duprez, G. Blanchard, and P. Isnard, "Total oxidation of acetic acid in aqueous solutions over noble metal catalysts," Journal of Catalysis, vol. 177 , no. 2, pp. 378-385, 1998.

[8] H. Nonaka and Y. Matsumura, "Electrochemical oxidation of carbon monoxide, methanol, formic acid, ethanol, and acetic acid on a platinum electrode under hot aqueous conditions," Journal of Electroanalytical Chemistry, vol. 520, no. 1-2, pp. 101$110,2002$.

[9] T. M. C. Hoang, B. Geerdink, J. M. Sturm, L. Lefferts, and K. Seshan, "Steam reforming of acetic acid-a major component in the volatiles formed during gasification of humin," Applied Catalysis B: Environmental, vol. 163, pp. 74-82, 2015.

[10] F. G. E. Nogueira, P. G. M. Assaf, H. W. P. Carvalho, and E. M. Assaf, "Catalytic steam reforming of acetic acid as a model compound of bio-oil," Applied Catalysis B: Environmental, vol. 160-161, no. 1, pp. 188-199, 2014.

[11] S. Trevin, F. Bedioui, M. Guadalupe Gomez Villegas, and C. Bied-Charreton, "Electropolymerized nickel macrocyclic complex-based films: design and electrocatalytic application," Journal of Materials Chemistry, vol. 7, no. 6, pp. 923-928, 1997.

[12] S. Seelan, A. K. Sinha, D. Srinivas, and S. Sivasanker, "Spectroscopic investigation and catalytic activity of copper(II) phthalocyanine encapsulated in zeolite Y," Journal of Molecular Catalysis A: Chemical, vol. 157, no. 1-2, pp. 163-171, 2000.

[13] J. H. Zagal, S. Griveau, J. F. Silva, T. Nyokong, and F. Bedioui, "Metallophthalocyanine-based molecular materials as catalysts for electrochemical reactions," Coordination Chemistry Reviews, vol. 254, no. 23-24, pp. 2755-2791, 2010.

[14] F. Matemadombo, C. Apetrei, T. Nyokong, M. L. RodríguezMéndez, and J. A. de Saja, "Comparison of carbon screenprinted and disk electrodes in the detection of antioxidants using CoPc derivatives," Sensors and Actuators B: Chemical, vol. 166-167, pp. 457-466, 2012.

[15] M. Pontié, C. Gobin, T. Pauporté, F. Bedioui, and J. Devynck, "Electrochemical nitric oxide microsensors: sensitivity and selectivity characterisation," Analytica Chimica Acta, vol. 411, no. 1-2, pp. 175-185, 2000.

[16] F. Bedioui, J. Devynck, and C. Bied-Charreton, "Immobilization of metalloporphyrins in electropolymerized films: design and applications," Accounts of Chemical Research, vol. 28, no. 1, pp. 30-36, 1995.

[17] A. Arrieta, M. L. Rodriguez-Mendez, and J. A. de Saja, "Langmuir-Blodgett film and carbon paste electrodes based on phthalocyanines as sensing units for taste," Sensors and Actuators B: Chemical, vol. 95, no. 1-3, pp. 357-365, 2003.

[18] F. Bedioui, S. Griveau, T. Nyokong et al., "Tuning the redox properties of metalloporphyrin- and metallophthalocyaninebased molecular electrodes for the highest electrocatalytic activity in the oxidation of thiols.," Physical Chemistry chemical Physics, vol. 9, no. 26, pp. 3383-3396, 2007.

[19] A. A. Gaberkorn, I. A. Popkova, P. A. Stuzhin, and C. Ercolani, "Study of basic properties of tert-butyl-substituted tribenzo(1,2,5-thiadiazolo)porphyrazines," Russian Journal of General Chemistry, vol. 76, no. 9, pp. 1494-1503, 2006.

[20] P. A. Stuzhin, "Azaporphyrins and phthalocyanines as multicentre conjugated ampholites," Journal of Porphyrins and Phthalocyanines, vol. 3, no. 6-7, pp. 500-513, 1999. 
[21] S. Z. Topal, F. Yuksel, A. G. Gürek, K. Ertekin, B. Yenigül, and V. Ahsen, "Spectroscopic probing of acid-base properties and photocharacterization of phthalocyanines in organic solvents and polymer matrices," Journal of Photochemistry and Photobiology A: Chemistry, vol. 202, no. 2-3, pp. 205-213, 2009.

[22] F. Conzuelo, M. Gamella, S. Campuzano, A. J. Reviejo, and J. M. Pingarrón, "Disposable amperometric magneto-immunosensor for direct detection of tetracyclines antibiotics residues in milk," Analytica Chimica Acta, vol. 737, pp. 29-36, 2012.

[23] M. Moreno-Guzmán, A. González-Cortés, P. YáñezSedeño, and J. M. Pingarrón, "A disposable electrochemical immunosensor for prolactin involving affinity reaction on streptavidin-functionalized magnetic particles," Analytica Chimica Acta, vol. 692, no. 1-2, pp. 125-130, 2011.

[24] C. Pellicer, A. Gomez-Caballero, N. Unceta, M. A. Goicolea, and R. J. Barrio, "Using a portable device based on a screen-printed sensor modified with a molecularly imprinted polymer for the determination of the insecticide fenitrothion in forest samples," Analytical Methods, vol. 2, no. 9, pp. 1280-1285, 2010.

[25] H. Li and T. F. Guarr, "Formation of electronically conductive thin films of metal phthalocyanines via electropolymerization," Journal of the Chemical Society, Chemical Communications, no. 13, pp. 832-834, 1989.

[26] Z. Biyıklığlu, V. Çakir, F. Demir, and A. Koca, "New electropolymerizable metal-free and metallophthalocyanines bearing 2-[3-(diethylamino)phenoxy]ethoxy substituents," Synthetic Metals, vol. 196, pp. 166-172, 2014.

[27] J. Tkac and T. Ruzgas, "Dispersion of single walled carbon nanotubes. Comparison of different dispersing strategies for preparation of modified electrodes toward hydrogen peroxide detection," Electrochemistry Communications, vol. 8, no. 5, pp. 899-903, 2006.

[28] Z. Biyiklioğlu and D. Çakir, "New electropolymerizable metalfree and metallophthalocyanines bearing 2,3-bis[3-(diethylamino)phenoxy]propoxy substituents," Dyes and Pigments, vol. 100, no. 1, pp. 150-157, 2014.

[29] V. Çakır, F. Demir, Z. Bıyıklığlu, A. Koca, and H. Kantekin, "Synthesis, characterization, electrochemical and spectroelectrochemical properties of metal-free and metallophthalocyanines bearing electropolymerizable dimethylamine groups," Dyes and Pigments, vol. 98, no. 3, pp. 414-421, 2013.

[30] K. De Wael, P. Westbroek, A. Adriaens, and E. Temmerman, "Role of gold adatoms in the stability and electrochemical behavior of gold surfaces modified with phthalocyanines," Electrochemical and Solid-State Letters, vol. 8, no. 4, pp. C65C68, 2005.

[31] G. Ilangovan, J. L. Zweier, and P. Kuppusamy, "Electrochemical preparation and EPR studies of lithium phthalocyanine: evaluation of the nucleation and growth mechanism and evidence for potential-dependent phase formation," The Journal of Physical Chemistry B, vol. 104, no. 17, pp. 4047-4059, 2000.

[32] K. De Wael, P. Westbroek, and E. Temmerman, "Study of the deposition of a cobalt(II)tetrasulfophthalocyanine layer at gold surfaces in alkaline solution," Journal of Electroanalytical Chemistry, vol. 567, no. 2, pp. 167-173, 2004.

[33] P. Tau and T. Nyokong, "Electrocatalytic activity of arylthio tetra-substituted oxotitanium(IV) phthalocyanines towards the oxidation of nitrite," Electrochimica Acta, vol. 52, no. 13, pp. 4547-4553, 2007.

[34] B. O. Agboola, K. I. Ozoemena, and T. Nyokong, "Electrochemical properties of benzylmercapto and dodecylmercapto tetra substituted nickel phthalocyanine complexes: electrocatalytic oxidation of nitrite," Electrochimica Acta, vol. 51, no. 28, pp. 6470-6478, 2006.

[35] A. Ndiaye, P. Bonnet, A. Pauly et al., "Noncovalent functionalization of single-wall carbon nanotubes for the elaboration of gas sensor dedicated to BTX type gases: the case of toluene," The Journal of Physical Chemistry C, vol. 117, no. 39, pp. 20217-20228, 2013.

[36] C. Medina-Plaza, C. García-Cabezón, C. García-Hernández et al., "Analysis of organic acids and phenols of interest in the wine industry using Langmuir-Blodgett films based on functionalized nanoparticles," Analytica Chimica Acta, vol. 853, no. 1, pp. 572-578, 2015. 

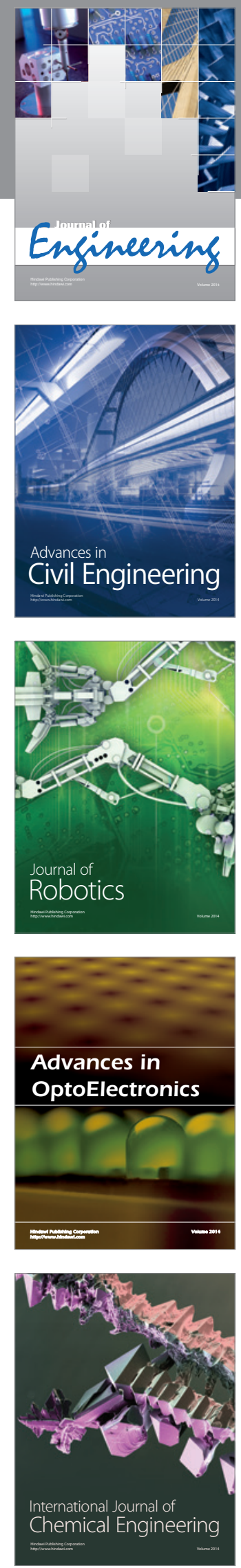

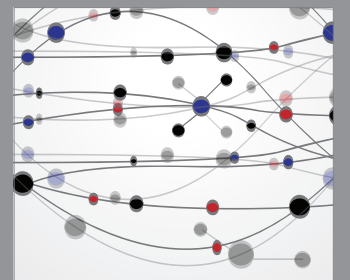

The Scientific World Journal
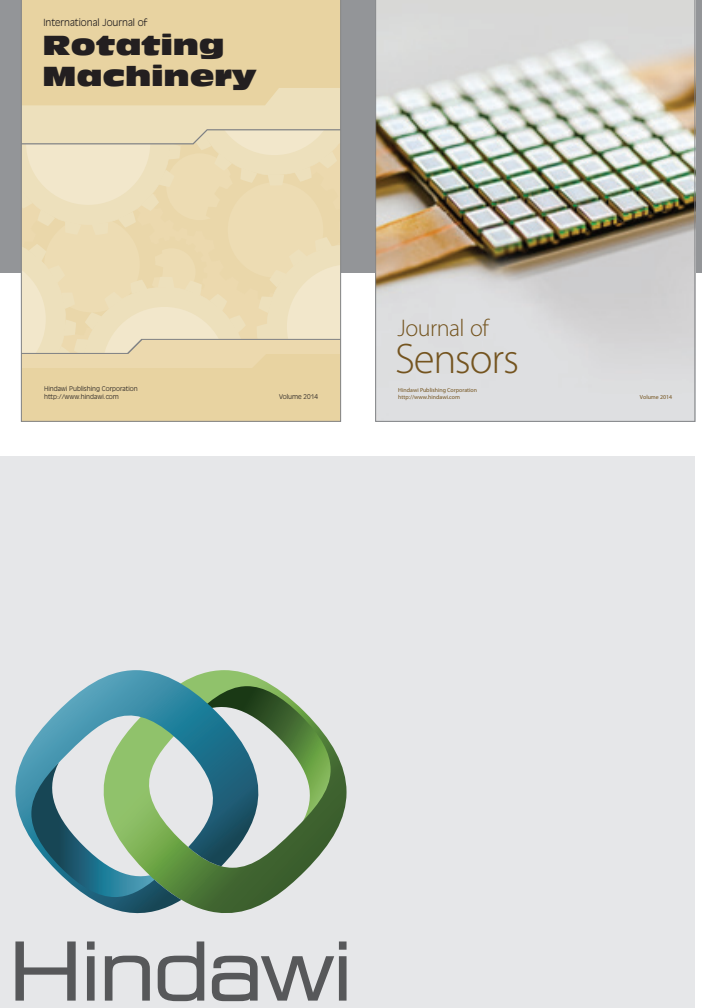

Submit your manuscripts at http://www.hindawi.com
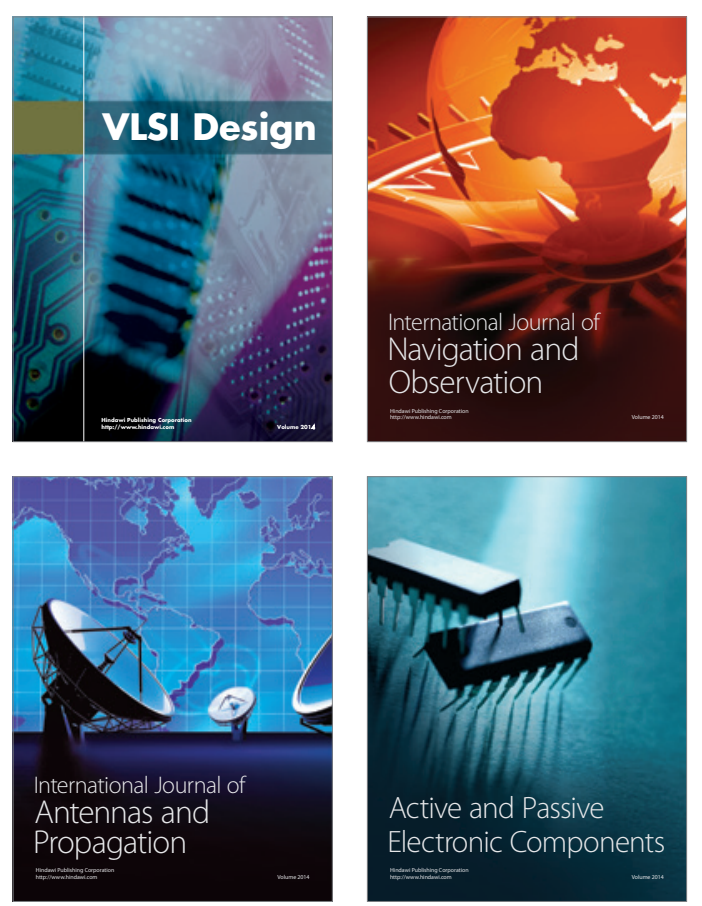
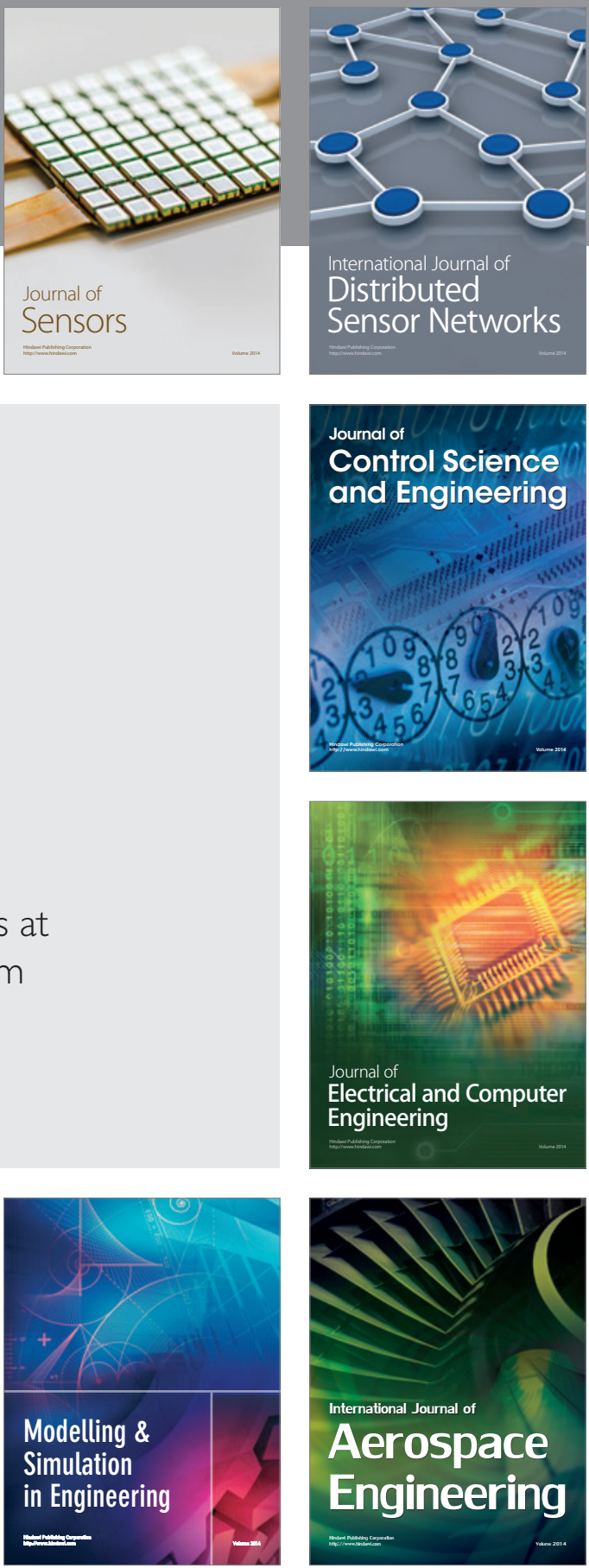

Journal of

Control Science

and Engineering
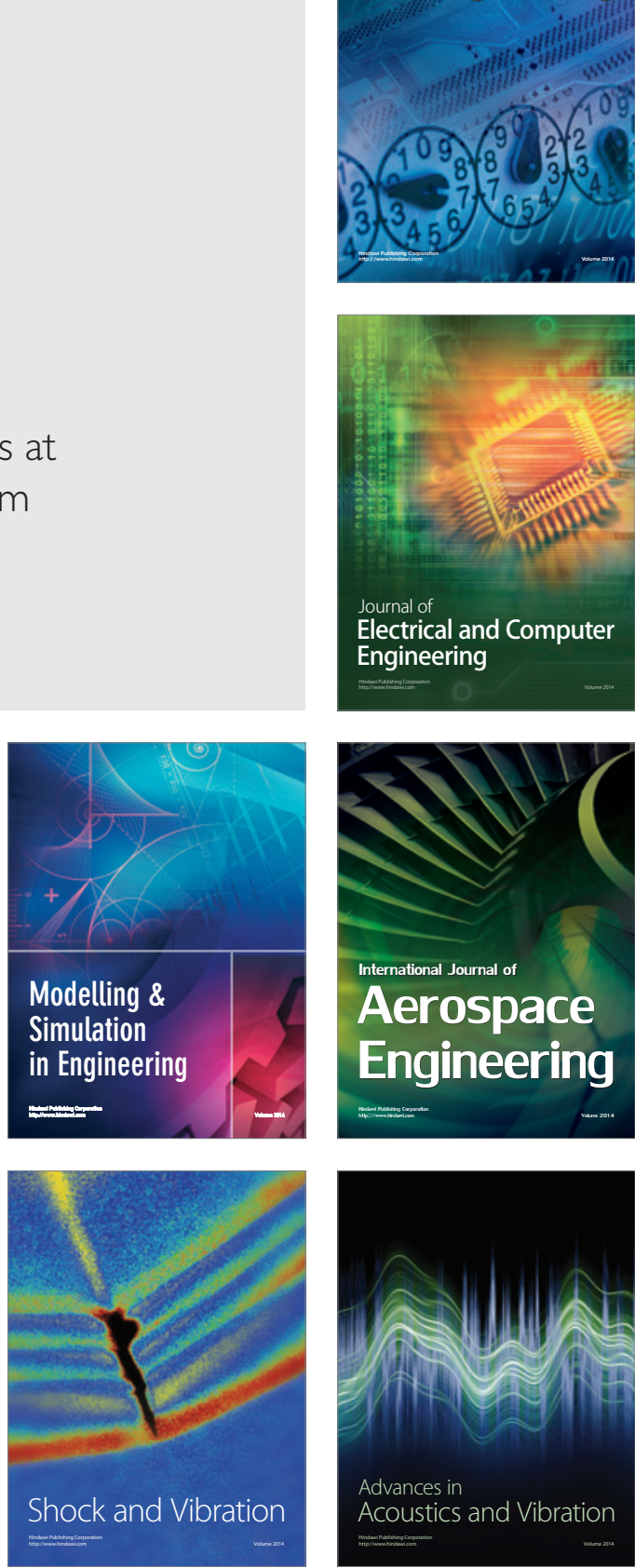